\title{
Eğitim Programları ve Öğretim Alanında Yapılan Doktora Tezlerinin İncelenmesi: 2015-2019
}

\author{
DOI: $10.26466 /$ opus.647030
}

*

\section{Nese Özkal*}

* Doç. Dr., Alanya Alaaddin Keykubat Üniversitesi, Eğitim Fakültesi, Alanya/Antalya/Türkiye E-Posta: neșe.ozkal@alanya.edu.tr

ORCID: $\underline{0000-0002-7854-5276}$

\section{$\ddot{O} z$}

Bu çalışmada 2015-2019 yılları arasında eğitim programları ve öğretim alanında yapılan doktora tezleri çeşitli değgişkenlere göre incelenmiştir. Araştırma da nitel araştırma yöntemi ve doküman incelemesi tekniği kullanılmıştır. Bu araştırmada dokümanlar YÖK tez veri tabanından ulaşılan, Türkiye'de 2015-2019 yılları arasında EPÖ alanında yapılmış ve erişime açık olan 201'i doktora tezidir. Araştırmada 201 doktora tezinden elde edilen veriler betimsel ve içerik analizi yoluyla çözümlenmiştir. Araştırma sonucuna göre en fazla tezin 2018 yılında yapıldığı, kadın ve erkek araştırmacı saysının yakın, erkek danışmanların sayısının fazla, danışmanların daha çok profosör ünvanlı olduğu belirlenmiştir. Tezlerde en çok karma, en az nitel yöntemin kullanildı̆̆ fazla durum çalışmasının kullanıldığı belirlenmiştir. Tezlerin en fazla öğretmenler üzerinde yapıldığı, örneklem büyüklüklerinin en fazla 1-50 arasında olduğu, araştırma verilerinin en fazla ölçek ve görüşme formları ile toplandığı, araştırma verilerinin en fazla içerik analizi ile çözümlendiği belirlenmiştir. Tezlerde en çok öğretme-öğrenme yaklaşımları, öğretmen, program geliştirme, program değerlendirme en az çok kültürlü eğitim, uluslararasılaşma, strateji öğretimi, karşılaştırmalı eğitim konularının çalışıldı̆̆ belirlenmiştir.

Anahtar Kelimeler: Eğitim programı, doktora tezi, araştırma eğilimi 


\title{
Investigating the Doctoral Theses in The Field of Curriculum and Instruction:2015-2019
}

\begin{abstract}
This study examined the doctoral theses conducted in the field of educational programs and teaching for the period of 2015-2019 for different variables Qualitative research method and document review technique were used in the research. Also documents used as a resource are 201 thesis which are written in the field of Curriculum and Instruction and opened to access between 2015 - 2019 reached through The Council of Higher Education data base. The research analyzed the data obtained from 201 doctoral dissertations by using descriptive and content analysis. According to results, it was determined that the highest number of dissertations was written in 2018, the number of male and female researchers was close, the number of male advisors was higher and advisors were mostly professors. It was identified that mixed method was preferred in theses the most while qualitative method was used the least and that survey design was used the most in terms of quantitative methods while case study method was utilized the most in terms of qualitative methods. It was found that the majority of the theses was conducted on teachers, the sample sizes were between 1-50 at the most, the research data were mostly collected with the use of scales and interview forms, and content analysis was mostly used in data analysis. The fields of study in dissertations were mostly teaching-learning approaches, teachers, curriculum development, and curriculum evaluation whereas multicultural education, internationalization, strategy teaching and comparative education were the areas that were studied the least.
\end{abstract}

Keywords: Curriculum, PhD thesis, research tendency 


\section{Giriş}

Alanyazın taraması bilimsel çalışmaların önemli bir basamağıdır. Araştırmacılar çalışacakları konularla ilgili olarak önceden yapılmış araştırmaları inceler ve ilgili alanyazın ışığında çalışmalarını temellendirirler. Alanyazın taraması içinde yayımlanmış kitaplar, makaleler, araştırma raporları vb. yazılı kaynaklar yer almaktadır. Yazılı kaynaklar araştırmacılara kaynak teşkil etmenin yanında, yol gösterirler ve alandaki araştırma eğilimlerinin belirlenmesini sağlarlar. Lisansüstü tezlerde bilimsel araştırmalarda sıkça başvurulan yazılı kaynaklardandır.

Türkiye'de 1971 yılında kurulan ve lisans düzeyinde eğitim veren Eğitim Programları ve Öğretim (EPÖ) programının 1997 yılında lisans bölümleri kapatılmıştır. 1997 sonrasında EPÖ programı lisansüstü düzeyde öğrenci kabul etmekte ve yüksek lisans ve doktora tezleri ile alana katkı sağlamaktadır (Kozikoğlu ve Senemoğlu, 2014). EPÖ anabilim dalı YÖK 2010 verilerine göre 52 üniversitede yer almaktadır (Erişti, 2013). Alanyazın incelendiğinde genelde eğitim bilimleri alanında (Karadağ (2009; Karadă̆, 2010; Tavşancıl vd., 2010) özelde ise Eğitim Programları ve Öğretim alanında lisansüstü tezlerin incelenerek alandaki araştırma eğilimlerinin belirlenmeye çalışıldığı görülmektedir (Altın, 2004; Bıkmaz, Aksoy, Tatar ve Altınyüzük, 2013; Demirhan İşcan ve Hazır Bıkmaz, 2012; Demirel, Ayvaz ve Köksal, 2008; Gömleksiz ve Bozpolat, 2013; Özdemir ve Ar1 ,2008; Saracaloğlu ve Dursun, 2010; Schreglmann, 2016; Yetkiner, Acar, Erdol ve Ünlü, 2019). Özellikle bir bilim dalının en üst öğrenim düzeyini temsil eden doktora tezleri araştırmacıların başvuracağı kaynaklar arasında en önemlilerinden biri olarak görülebilir. EPÖ Doktora tezlerinin incelenmesi ile ilgili olarak en kapsamlı yapılan çalışmalar ise; Bıkmaz vd (2009) 1974-2009 ve Kozikoğlu ve Senemoğlu (2014) nun 2009-2014 yılları arasındaki EPÖ doktora tezlerindeki araştırma eğilimlerini inceledikleri çalışmalarıdır. Bıkmaz vd.'nin (2013) çalışmalarını diğer benzer çalışmalara göre öne çkaran, örnekleme aldıkları doktora tezleri sayısının diğerlerine oranla daha fazla olması ve 1974-2009 yıllarını kapsayan uzun bir dönemi incelemesidir. Kozikoğlu ve Senemoğlu (2014) çalışmasını ise 2009-2014 yılları arasındaki beş yıllık dönemdeki doktora tezlerini inceleyerek Bıkmaz vd (2013) çalışmasının devamını sağlamaya çalışması ön plana çıkarmaktadır. Alanyazında araştırma eğilimlerinin belirlenmesi için bu tip nitelik gerekti- 
ren çalışmaların düzenli olarak beş yıllık dönemlerde yapılması önerilmektedir (Karadağ, 2010). Bu nedenlerle bu çalışmada bu iki çalışmanın devamı ve tamamlayıcısı niteliğinde 2015-2019 EPÖ alanında yapılmış olan doktora tezlerindeki güncel araştırma eğilimlerinin belirlenmesi amaçlanmıştır. Araştırmanın alandaki eğilimlerin, boşlukların belirlenlenmesinde, EPÖ alanında çalışan araştırmacılara araştırmaların düzenlemede yol göstereceği ve bu yolla alana katkı sağlayacağı umulmaktadır.

\section{Yöntem}

Araştırma da nitel araştırma yöntemi ve doküman incelemesi tekniği kullanılmıştır. Bu araştırmada dokümanlar YÖK tez veri tabanından ulaşılan, Türkiye'de 2015-2019 yılları arasında EPÖ alanında yapılan doktora tezleridir. Araştırma da 2015-2019 yılları arasında EPÖ doktora alanında yapılmış olan tüm tezlerin incelenmesi amaçlanmıştır. Ancak doktora tezlerin bir bölümünün erişiminin kısıtlı olması nedeniyle tümüne ulaşılamamıştır. Bu nedenle araştırma kapsamına 2015-2019 yılları arasında EPÖ alanında yapılmış ve erişime açık olan 201'i doktora tezi dahil edilmiştir.

\section{Verilerin Kodlanması ve Analizi}

Araştırma verilerinin analizi örneklemde yer alan 201 doktora tezinin betimsel ve içerik analizi ile incelenerek gerçekleştirilmiştir. Verilerin analizi için öncelikle alanyazında farklı konu alanlarında araştırma eğilimlerinin belirlenmesi için yapılmış olan yayınlar incelenmiştir (Bıkmaz vd. 2009; Kozikoğlu ve Senemoğlu, 2015; Ozan ve Köse, 2014; Boyacı ve Demirkol, 2018). $\mathrm{Bu}$ inceleme sonucunda çalışmalarda yer alan kategoriler listelenmiştir. Listelenen kategoriler incelenerek araştırma da tezlerin incelenmesinde kullanılacak olan kategoriler ve bunlara ilişkin temaların ve kodların yer aldığ 1 "tez inceleme formu" hazırlanmıştır. Araştırmada, araştırmacı ve danışman cinsiyeti, araştırmacı unvanı, araştırma deseni, örneklem türü, örneklem büyüklüğü, veri toplama araçları, veri çözümleme teknikleri, araştırma konusu, anahtar sözcükler, üniversite ve yıl kategorilerinin yer alması kararlaştırılmıştır. "Araştırma konusu" dışındaki kategoriler "Tez inceleme formu" nda yer alan, önceden belirlenmiş temalara ve kodlara göre incelenerek çözümle- 
meler yapılmıştır. Araştırma konusu temasına ait kodlamalar ise içerik analizi ile incelenmiştir. Araştırma konusu temasi için öncelikle tüm tezlerde kullanılan anahtar kelimeler, tez başlığ 1 ve tezin yöntem bölümü içerik analizi ile incelenerek konu kategorisi altında temalar, temalara ait alt temalar ve alt temalarla ilişkili kodlar belirlenmiştir. Verilerin kodlanması ve çözümlenmesi araştırmacı tarafından gerçekleştirilmiştir. Kodlamaların güvenilirliğini belirlemek için EPÖ alan uzmanı bir öğretim üyesi ile güvenirlik çalışması yapılmıştır. Araştırmacının "tez inceleme formuna" göre incelediği tezler arasından raslantısal olarak seçilen 21 tez (örneklemin \%10'u), alan uzmanınca da kodlanmış ve yapılan kodlamalar arasında uyum yüzdesi hesaplanmıştır (Miles ve Huberman, 1994). Kodlamalar arası uyum yüzdesi 90 olarak belirlenmiştir. Ayrıca "araştırma konusu" teması altında yapılan tüm alt tema kodlamaları da alan uzmanınca kontrol edilerek güvenirlik sağlanmaya çalışılmıştır. Araştırmada temalara ait kodlamalar excel programına aktarılarak, her bir temaya ait frekanslar (f) ve yüzdeler (\%) hesaplanmıştır.

\section{Bulgular}

2015-2019 yılları arasında yapılan EPÖ doktora tezleri "Tezlerin yapıldığı üniversiteler ve kabul yılı", "Araştırmacı cinsiyeti", "Danışman cinsiyeti", "Danışman unvanı", "Araştırma yöntem ve desenleri", "Nitel desenler", "Örneklem büyüklüğü", "Örneklem grupları", "Veri toplama araçları”, "Veri Analizi Teknikleri" ve "Konu alanları" başlıklarında incelenmiş ve sıra ile sunulmuştur.

\section{Tezlerin Yapıldı̆̆ı Üniversiteler Ve Kabul Yılı}

Tablo 1'e göre incelenen 201 doktora tezinin 45'i (\%22,39) 2015'de, 54'ü (\%26,87) 2016, 27'si (\%13,43) 2017, 60'1 (\%29,85) 2018, 15'i (\%7,46) 2019 yılında tamamlanmıştır. Tablo 1'e göre en fazla tezin tamamladığı yıl 2018 yılıdır. Örneklemde yer alan tezler üniversiteler açısından incelendiğinde ise 2015 yılında $(n=45)$ en fazla Abant İzzet Baysal Üniversitesi'nde 5 (\%11,11), Dicle, Gaziantep ve Necmettin Erbakan Üniversitesi'nde ise 4 'er tezin $(\% 8,89)$ tamamlandığı görülmektedir. 
Tablo 1. 2015-19 yılları arasında EPÖ alanında yapılan doktora tezlerinin dă̆ılımı

\begin{tabular}{llllllll}
\hline & 2015 & 2016 & 2017 & 2018 & 2019 & \multicolumn{3}{l}{ Toplam } \\
\hline Üniversite & $\mathrm{f}$ & $\mathrm{f}$ & $\mathrm{f}$ & $\mathrm{f}$ & $\mathrm{f}$ & $\mathrm{f}$ & $\%$ \\
\hline Abant İzzet Baysal & 5 & 1 & 3 & 4 & - & 13 & 6,47 \\
Afyon & - & 1 & - & - & - & 1 & 0,50 \\
Anadolu & 1 & 4 & - & 2 & 1 & 8 & 3,98 \\
Ankara & 1 & 3 & 2 & 1 & - & 7 & 3,48 \\
Atatürk & 1 & - & 1 & 1 & - & 3 & 1,49 \\
Adnan Menderes & 1 & 1 & 2 & 5 & - & 9 & 4,48 \\
Balikesir & 1 & 3 & 2 & 1 & - & 7 & 3,48 \\
Bilkent & 1 & 1 & - & 2 & - & 4 & 1,99 \\
Çanakkale & - & 3 & 1 & 1 & - & 5 & 2,49 \\
Çukurova & 3 & 5 & 3 & 2 & - & 13 & 6,47 \\
Dicle & 4 & 4 & 1 & - & - & 9 & 4,48 \\
Ege & - & - & - & 1 & - & 1 & 0,50 \\
Firat & 2 & 2 & - & 3 & 3 & 10 & 4,98 \\
Gazi & 1 & 4 & 1 & 3 & 1 & 10 & 4,98 \\
Gaziantep & 4 & 6 & - & 2 & 1 & 13 & 6,47 \\
Gaziosmanpaşa & 1 & - & - & 5 & 3 & 9 & 4,48 \\
Hacettepe & 4 & 1 & 3 & 5 & - & 13 & 6,47 \\
İnönü & 3 & 1 & - & 2 & - & 6 & 2,99 \\
Mersin & 1 & - & 1 & 3 & - & 5 & 2,49 \\
Necmettin Erbakan & 4 & 5 & - & 2 & 1 & 12 & 5,97 \\
Osmangazi & 3 & 2 & 2 & 7 & 4 & 18 & 8,96 \\
OTTÜ & 1 & 3 & 3 & 1 & 1 & 9 & 4,48 \\
Yildız & 2 & 2 & 1 & 4 & - & 9 & 4,48 \\
Yüzüncü Yıl & 1 & 2 & 1 & 3 & - & 7 & 3,48 \\
Toplam & 5 & 54 & 27 & 60 & 15 & 201 & 100 \\
\hline
\end{tabular}

2016 yılında ( $n=54)$ en fazla Gaziantep Üniversitesi'nde 6 (\%11,11), Çukurova ve Necmettin Erbakan Üniversitesi'nde 5'er $(\% 9,26)$ tezin tamamlandığ 1 görülmektedir. 2017 yılında ( $\mathrm{n}=27)$ en fazla Abant İzzet Baysal, Çukurova, Hacettepe, Ortadoğu Teknik Üniversitesi'nde 3'er tezin $(\% 11,11)$ tamamlandığı görülmektedir. 2018 yılında $(\mathrm{n}=60)$ en fazla Osmangazi Üniversitesinde 7 (\%11,67), Gaziosmanpaşa, Hacettepe ve Adnan Menderes Üniversitelerinde 5'er tezin $(\% 8,33)$ tamamlandığı görülmektedir. 2019 yılında $(n=15)$ ise en fazla Osmangazi Üniversitesi'nde $4(\% 26,67)$, Firat ve Gaziosmanpaşa Üniversitelerinde ise 3'er (\%20) tezin tamamlandığı görülmektedir. Genel olarak 2015-2019 yılları arasında araştırmada yer alan 201 tezin en fazla Osmangazi Üniversitesi'nde 18 (\%8,96), Abant İzzet Baysal, Çukurova, Hacettepe, Gaziosmanpaşa ve Gaziantep üniversitesinde ise 13'er tezin $(\% 6,47)$ tamamlandığı görülmektedir. 


\section{Araştırmacı Cinsiyeti}

Tablo 2 incelendiğinde araştırma örnekleminde yer alan 201 tezinin 107'si kadın (\%53,23), 94'ü erkek araştırmacılar (\%46,77) tarafından yapıldığı görülmektedir.

Tablo 2. Araştırmacı cinsiyetine göre tezlerin dağılımı

\begin{tabular}{lllll}
\hline Üniversite & $\mathrm{f}$ & $\%$ & $\mathrm{f}$ & $\%$ \\
\hline Abant İzzet Baysal & 5 & 38,46 & 8 & 61,54 \\
Adnan Menderes & 6 & 66,67 & 3 & 33,33 \\
Afyon & - & - & 1 & 100,00 \\
Anadolu & 5 & 62,50 & 3 & 37,50 \\
Ankara & 5 & 71,43 & 2 & 28,57 \\
Atatürk & 1 & 33,33 & 2 & 66,67 \\
Balıkesir & 2 & 28,57 & 5 & 71,43 \\
Bilkent & 2 & 50,00 & 2 & 50,00 \\
Çanakkale & 4 & 80,00 & 1 & 20,00 \\
Çukurova & 10 & 76,92 & 3 & 23,08 \\
Dicle & 2 & 28,57 & 7 & 77,78 \\
Ege & - & - & 1 & 100,00 \\
Firat & 5 & 50,00 & 5 & 50,00 \\
Gazi & 5 & 50,00 & 5 & 50,00 \\
Gaziantep & 8 & 61,54 & 5 & 38,46 \\
Gaziosmanpaşa & 4 & 44,44 & 5 & 55,56 \\
Hacettepe & 7 & 53,85 & 6 & 46,15 \\
İnönü & 2 & 33,33 & 4 & 66,67 \\
Mersin & 2 & 40,00 & 3 & 60,00 \\
Necmettin Erbakan & 4 & 33,33 & 8 & 66,67 \\
Osmangazi & 10 & 55,56 & 8 & 44,44 \\
Ottü & 9 & 100,00 & - & - \\
Yılldız & 5 & 55,56 & 4 & 44,44 \\
Yüzüncü Yıl & 4 & 57,14 & 3 & 42,86 \\
Toplam & 107 & 53,3 & 94 & 46,77 \\
\hline
\end{tabular}

\section{Danışman cinsiyeti}

Tablo 3 incelendiğinde araştırma örnekleminde yer alan 201 doktora tezinin 66 'sının kadın $(\% 32,84)$ 135'i erkek danışman öğretim üyesi $(\% 67,16)$ tarafından yönetildiği görülmektedir. 
Tablo 3. Danışman cinsiyetine göre tezlerin dă̆ılımı

\begin{tabular}{lllll}
\hline \multicolumn{2}{c}{ Üniversite } & $\mathrm{f}$ & $\%$ & \multicolumn{2}{c}{ Erkek } \\
\hline Abant İzzet Baysal & 3 & 23,08 & $\mathrm{f}$ & $\%$ \\
Adnan Menderes & 4 & 44,44 & 10 & 76,92 \\
Afyon & - & - & 5 & 55,56 \\
Anadolu & 1 & 12,50 & 1 & 100,00 \\
Ankara & 6 & 85,71 & 7 & 87,50 \\
Atatürk & - & - & 1 & 16,67 \\
Balıkesir & 1 & 14,29 & 3 & 100,00 \\
Bilkent & - & - & 6 & 85,71 \\
Çanakkale & 2 & 40,00 & 4 & 100,00 \\
Çukurova & 3 & 23,08 & 3 & 60,00 \\
Dicle & - & - & 10 & 76,92 \\
Ege & 1 & 100,00 & 9 & 100,00 \\
Firat & 1 & 10,00 & - & \\
Gazi & 3 & 30,00 & 9 & 90,00 \\
Gaziantep & 3 & 23,08 & 7 & 70,00 \\
Gaziosmanpaşa & 4 & 44,44 & 10 & 76,92 \\
Hacettepe & 9 & 69,23 & 5 & 55,56 \\
İnönü & - & & 4 & 30,77 \\
Mersin & 5 & 100,00 & 6 & 100,00 \\
Necmettin Erbakan & 3 & 25,00 & & \\
Osmangazi & 8 & 44,44 & 9 & 75,00 \\
Ottü & 4 & 44,44 & 10 & 55,56 \\
Yllldız & 3 & 33,33 & 5 & 55,56 \\
Yüzüncü Yıl & 2 & 28,57 & 6 & 66,67 \\
Toplam & 66 & 32,84 & 5 & 71,43 \\
\hline
\end{tabular}

\section{Danışman Ünvanı}

Tablo 4 incelendiğinde araştırma örnekleminde yer alan 201 doktora tezinin 96'sının Profosör (\%47,76), 72'sinin doçent (\%35,82) ve 33'ünün Doktor Öğretim üyesi tarafından yönetildiği görülmektedir. 
Tablo 4. Danışman unvanına göre tezlerinin dağılımı

\begin{tabular}{llll}
\hline & Profösör & Doçent & Dr. Öğr. Üyesi \\
\hline Üniversite & $\mathrm{f}$ & $\mathrm{f}$ & $\mathrm{f}$ \\
\hline Abant İzzet Baysal & 2 & 5 & 6 \\
Adnan Menderes & 8 & 1 & - \\
Afyon & - & 1 & - \\
Anadolu & 5 & 3 & - \\
Ankara & 5 & 1 & 1 \\
Atatürk & 1 & 2 & - \\
Balıkesir & 1 & 6 & - \\
Bilkent & 1 & - & 3 \\
Çanakkale & 2 & 2 & 1 \\
Çukurova & 6 & 2 & 5 \\
Dicle & 5 & 3 & 1 \\
Ege & - & 1 & - \\
Frrat & 5 & 3 & 2 \\
Gazi & 9 & 1 & - \\
Gaziantep & - & 13 & - \\
Gaziosmanpaşa & 1 & 2 & 6 \\
Hacettepe & 8 & 5 & - \\
İönü & 2 & 1 & 3 \\
Mersin & 4 & - & 1 \\
Necmettin Erbakan & 7 & 5 & - \\
Osmangazi & 14 & 4 & - \\
Ottü & 6 & 3 & - \\
Yılldı̈ & 2 & 5 & 2 \\
Yüzüncü Yl & 2 & 3 & 2 \\
Toplam & 96 & 72 & 33 \\
\hline
\end{tabular}

\section{Araştırma Yöntem Ve Desenleri}

Örneklemde yer alan 201 doktora tezi araştırma yöntemleri açısından incelendiğinde $84^{\prime}$ ünün karma $(\% 41,79)$, 64'ünün nicel $(\% 31,84)$ ve $51^{\prime}$ inin $(\% 25,37)$ nitel yöntemle yapıldığı belirlenmiştir. Tablo 5 'e göre örneklemde yer alan tezler tüm üniversiteler açısından birlikte ele alındığında nicel yöntemlerden deneysel desende en fazla tezin Abant İzzet Baysal Üniversitesi'nde $(n=5)$ yapılmış olduğu görülmektedir. Nicel yöntemlerden betimsel desende en fazla tez Hacettepe ve Gazi $(n=6)$ üniversitelerinde yapılmıştır. Nitel yöntemle Çukurova Üniversitesi'nde (n=9), Karma yöntemle ise en fazla yapılan tez Osmangazi Üniversitesi'ndedir. 
Tablo 5. Yapılan tezlerin araştırma yöntemlerine göre dağılımı

\begin{tabular}{llllll}
\hline & Nicel & Nicel & Nitel & Karma & Toplam \\
& Denysel & Betimsel & & & \\
\hline Üniversite & $\mathrm{f}$ & $\mathrm{f}$ & $\mathrm{f}$ & $\mathrm{f}$ & $\mathrm{f}$ \\
Abant İzzet Baysal & 5 & 4 & 2 & 2 & 13 \\
Adnan Menderes & - & - & 4 & 5 & 9 \\
Afyon & - & - & - & 1 & 1 \\
Anadolu & - & 1 & 3 & 4 & 8 \\
Ankara & - & 1 & 2 & 4 & 7 \\
Atatürk & 1 & - & - & 2 & 3 \\
Balıkesir & 1 & 2 & 1 & 3 & 7 \\
Bilkent & - & - & 1 & 3 & 4 \\
Çanakkale & 1 & 1 & - & 3 & 5 \\
Çukurova & 3 & - & 9 & 1 & 13 \\
Dicle & 1 & 5 & 3 & - & 9 \\
Ege & - & - & - & 1 & 1 \\
Firat & 1 & 3 & - & 6 & 10 \\
Gazi & - & 6 & 3 & 1 & 10 \\
Gaziantep & 2 & - & 7 & 4 & 13 \\
Gaziosmanpaşa & - & 1 & 2 & 6 & 9 \\
Hacettepe & - & 6 & 1 & 6 & 13 \\
İnönü & 1 & 1 & 1 & 3 & 6 \\
Mersin & - & - & - & 5 & 5 \\
N. Erbakan & 2 & 2 & 1 & 7 & 12 \\
Osmangazi & 2 & 4 & 4 & 8 & 18 \\
Ottü & - & 1 & 5 & 3 & 9 \\
Yllldiz & - & 2 & 2 & 5 & 9 \\
Yüzüncü Yil & 2 & 2 & - & 3 & 7 \\
Toplam & 22 & 42 & 51 & 84 & 201 \\
\hline & & & & &
\end{tabular}

Örneklemde yer alan 201 doktora tezi içerisinde yer alan 51 nitel araştırma desenleri açısından incelendiğinde, 26'sının (\%50,98) durum çalışması, $15^{\prime}$ inin $(\% 29,41)$ eylem araştırması, $7^{\prime}$ 'sinin (\% 13,73) olgubilim 3'ünün $(\% 5,88)$ doküman incelemesi deseniyle yapıldığı belirlenmiştir. İncelenen tezler tüm üniversiteler bağlamında ele alındığında olgubilim deseninde OTTÜ ve Ankara Üniversitelerinde $(n=2)$, durum çalışması deseninde OTTÜ $(n=3)$ ve Çukurova $(n=3$, eylem araştırması deseninde ise Çukurova Üniveritesi'nde $(n=6)$ en fazla tez yapıldığ yöntem olarak metasentez, 1 tezde ise döküman incelemesi kullanıldığı belirtilmiştir. Creswell (2013) anlatı, fenemoloji, kuram oluşturma, etnografik 
araştırma ve durum çalışması olarak 5 nitel araştırma yaklaşımı belirtmektedir. Dicle Üniversitesinde yapılmış olan üç tezle ilgili olarak Creswell (2013) sınıflaması içerisinde yer verilememiş ve diğer olarak belirtilmiştir.

Tablo 6. Tezlerin nitel araştıma desenlerine göre dağılımı

\begin{tabular}{|c|c|c|c|c|}
\hline & Olgubilim & Durum çalışması & Eylem Araştırması & Diğer \\
\hline Üniversite & $\mathrm{f}$ & $\mathrm{f}$ & $\mathrm{f}$ & $\mathrm{f}$ \\
\hline Abant İzzet Baysal & - & 2 & - & - \\
\hline Adnan Menderes & 1 & 2 & 1 & - \\
\hline Afyon & - & - & - & \\
\hline Anadolu & 1 & 2 & - & - \\
\hline Ankara & 2 & - & - & - \\
\hline Atatürk & - & - & - & \\
\hline Balıkesir & - & 1 & - & - \\
\hline Bilkent & - & 1 & - & - \\
\hline Çanakkale & - & - & - & \\
\hline Çukurova & - & 3 & 6 & - \\
\hline Dicle & - & - & - & 3 \\
\hline Ege & - & - & - & - \\
\hline Furat & - & - & - & - \\
\hline Gazi & 1 & 2 & - & - \\
\hline Gaziantep & - & 2 & 5 & - \\
\hline Gaziosmanpaşa & - & 2 & - & - \\
\hline Hacettepe & - & 1 & - & - \\
\hline İnönü & - & 1 & - & - \\
\hline Mersin & - & - & - & - \\
\hline Necmettin Erbakan & - & 1 & - & - \\
\hline Osmangazi & - & 1 & 3 & - \\
\hline Ottü & 2 & 3 & - & - \\
\hline Yilldiz & - & 2 & - & - \\
\hline Yüzüncü Yıl & - & - & - & - \\
\hline Toplam & 7 & 26 & 15 & 3 \\
\hline
\end{tabular}

\section{Örneklem Büyüklü̈̆̈̈}

Tablo 7 tezlerin örneklem büyüklükleri açısından incelendiğinde 52 tezin 150 (\%25,87), 46'sının 101-500 (\%22,89), 44'ünün 51-100 (\%21,89), 30'unun $(\% 14,93) 1001$ ve üstü, 29'unun 501-1000 (\%9,95) ve örneklem büyüklüklerine sahip oldukları görülmektedir. 
Tablo 7. Tezlerin örneklem büyüklüklerine göre dağılımı

\begin{tabular}{llllll}
\hline Üniversite & $1-50$ & $51-100$ & $101-500$ & $501-1000$ & 1000 ve üstü \\
\hline Abant İ. Baysal & - & 5 & 5 & 1 & 2 \\
A. Menderes & - & 4 & 4 & 1 & - \\
Afyon & 1 & - & - & - & - \\
Anadolu & 3 & - & 1 & 2 & 2 \\
Ankara & 2 & 2 & - & 3 & - \\
Atatürk & 1 & 2 & - & - & - \\
Balıkesir & 1 & 2 & 3 & 1 & - \\
Bilkent & - & 2 & 2 & - & - \\
Çanakkale & - & 2 & 1 & 2 & - \\
Çukurova & 10 & 2 & - & - & 1 \\
Dicle & 1 & 3 & - & 1 & 4 \\
Ege & - & - & - & - & 1 \\
Firat & 1 & 4 & 2 & 2 & 1 \\
Gazi & - & - & 6 & 3 & 1 \\
Gaziantep & 5 & 5 & 3 & - & - \\
Gaziosmanpaşa & 4 & 2 & 1 & 1 & 1 \\
Hacettepe & 2 & 1 & 2 & 3 & 5 \\
İönü & 3 & - & 1 & 1 & 1 \\
Mersin & - & 2 & - & 2 & 1 \\
N. Erbakan & 3 & 5 & 1 & - & 3 \\
Osmangazi & 4 & - & 8 & 2 & 4 \\
OTTÜ & 5 & - & 3 & - & 1 \\
Y1ldı̈ & 3 & - & 3 & 3 & - \\
Yüzüncü Yıl & 3 & 1 & - & 1 & 2 \\
Toplam & 52 & 46 & 44 & 30 & 29 \\
\hline & & & & & \\
\hline
\end{tabular}

\section{Örneklem Gruplarn}

Tezlerin örnekleminde yer alan gruplar açısından incelendiğinde tezlerin 77 'sinde $(\% 38,31)$ öğretmenlerin, 38'inde $(\% 18,91)$ öğretmen adaylarının, 35 'inde $(\% 17,41)$ ortaokul öğrencilerinin, 31'inde öğretim elemanlarının (\%15,42), 28'inde öğretmen adayları dışında kalan lisans öğrencilerinin $(\% 13,93), 25$ 'inde ise ilkokul ve ortaöğretim öğrencilerinin $(12,44)$ yer aldığ görülmektedir. İncelenen tezlerin örneklem grupları içerisinde en az mezunlar, vatandaş, fiziksel mekanlar ve işverenlerin $(\% 0,50)$ yer aldığı görülmektedir. 
Tablo 8. Tezlerin örneklem gruplarnna göre dağılımı

\begin{tabular}{lll}
\hline Örneklem grupları & $\mathrm{f}$ & $\%$ \\
\hline Öğretmenler & 77 & 38,31 \\
Öğretmen adayları & 38 & 18,91 \\
Ortaokul öğrencileri & 35 & 17,41 \\
Öğretim Elemanları & 31 & 15,42 \\
Lisans & 28 & 13,93 \\
İlkokul öğrencileri & 25 & 12,44 \\
Ortaöğretim öğrencileri & 25 & 12,44 \\
Okulöncesi öğrencileri & 4 & 1,99 \\
Lisansüstü & 3 & 1,49 \\
Yöneticiler & 11 & 5,47 \\
Veliler & 6 & 2,99 \\
Dokümanlar & 6 & 2,99 \\
Müfettişler & 3 & 1,49 \\
Sendika temsilcileri & 3 & 1,49 \\
İdari personel & 2 & 1,00 \\
Mezunlar & 1 & 0,50 \\
Vatandaş & 1 & 0,50 \\
İssveren & 1 & 0,50 \\
Fiziksel mekanlar & 1 & 0,50 \\
\hline
\end{tabular}

\section{Veri Analizi Teknikleri}

Tablo 9'a göre örneklemde yer alan tezlerde kullanılan veri çözümleme teknikleri açısından incelendiğinde tezlerin 117 'sinde $(\% 58,21)$ içerik çözümlemesi, 86 'sında t- Testi, 70 'inde $(\% 34,83)$ betimsel çözümleme, 68 'inde $(\% 30,83)$ frekans ve yüzde, 61'inde (\%30,35) Anova, 51'inde (\%25,37), Non parametrik testler kullanılmıştır. İncelenen tezlerde en az Kanonik korelasyon çözümlemesi ve Aşamalı doğrusal modellemenin $(\% 0,50)$ yer aldığı görülmektedir.

Tablo 9. Tezlerde kullanılan veri analizi tekniklerinin dağılımı

\begin{tabular}{lll}
\hline Veri analizi teknikleri & $\mathbf{f}$ & $\mathbf{\%}$ \\
\hline Frekans/yüzde & 68 & 33,83 \\
Korelasyon analizi & 21 & 10,45 \\
T testi & 86 & 42,79 \\
Anavo & 61 & 30,35 \\
Ancova & 17 & 8,46 \\
Manova & 18 & 8,96 \\
Regresyon analizi & 11 & 5,47 \\
Non parametrik testler & 51 & 25,37 \\
Path Analizi & 16 & 7,96 \\
Ki Kare & 5 & 2,49 \\
\hline
\end{tabular}




\begin{tabular}{lll}
\hline Fridman & 3 & 1,49 \\
Kanonik Korelasyon & 1 & 0,50 \\
Aşamalı doğrusal modelleme & 1 & 0,50 \\
İçerik analizi & 117 & 58,21 \\
Betimsel analiz & 70 & 34,83 \\
\hline
\end{tabular}

\section{Veri toplama araçlar}

Örneklemde yer alan tezler kullanılan veri toplama araçları açısından incelendiğinde tezlerin 133 'ünde $(\% 66,17)$ likert ölçek, 116 'sında $(\% 57,71)$ yarı yapılandırılmış ölçek, 52'sinde $(\% 25,87)$ katılımcı olmayan gözlem, 42'sinde $(\% 20,90)$ çoktan seçmeli başarı testi, 37'sinde (\%18,41) dökümanlar, 31'inde $(\% 14,43)$ günlüklerin kullanıldığı görülmektedir. En az fotoğraflar (\%1,99), öğrenci ürünleri $(\% 2,99)$, açık uçlu başarı testi $(\% 2,99)$ ve video kayıtları $(2,99)$ kullanıldığı belirlenmiştir.

Tablo 10. Tezlerde kullanılan veri toplama araçlarının dağılımı

\begin{tabular}{llll}
\hline & Veri toplama araçları & $\mathbf{f}$ & $\mathbf{\%}$ \\
\hline Anket/ölçek & Likert anket & 133 & 66,17 \\
& Açık uçlu anket & 12 & 5,97 \\
\hline & Yarı Yapılandırılmış Görüşme & 116 & 57,71 \\
Görüşme & Odak Grup görüşmesi & 25 & 12,44 \\
\hline \multirow{3}{*}{ Gözlem } & Yapılandırılmış görüş̧me & 11 & 5,47 \\
\hline Başarı testi & Katılımcı gözlem & 7 & 3,48 \\
& Katılımcı olmayan gözlem & 52 & 25,87 \\
\hline Dökümanlar & Çoktan seçmeli başarı testi & 42 & 20,90 \\
& Açık uçlu başarı testi & 6 & 2,99 \\
\hline & Dökümanlar & 37 & 18,41 \\
& Günlükler & 31 & 14,43 \\
Diğer & Dereceli Puanlama & 9 & 4,48 \\
& Değerlendirme formları & 9 & 4,48 \\
& Senaryolar & 8 & 3,98 \\
& Öğrenci ürünleri & 6 & 2,99 \\
& Video kayıtları & 6 & 2,99 \\
& Fotoğraflar & 4 & 1,99 \\
\hline
\end{tabular}




\section{Tezlerin Konu Alanları}

Tablo 11 incelendiğinde konu alanlarına göre en fazla çalışmanın sırasıyla; öğretme-öğrenme yaklaşımları (\%23,88), öğretmen (\%19,40), program geliştirme $(\% 11,44)$, program değerlendirme $(\% 10,95)$, öğrenci $(\% 6,47)$, değer eğitimi $(\% 4,98)$ ve Eğitim ve bilgi teknolojileri $(\% 4,98)$ ile ilgili yapılmıştır. En az çalışma ise sırasıyla eğitim programı $(3,98)$, çok kültürlü eğitim $(3,98)$, uluslararasılaşma (\%2,49), strateji öğretimi $(2,49)$ Karşılaştırmalı eğitim (\%1,99), üzerine yapılmış olduğu görülmektedir.

Tablo 11. Konu analizi dă̆̆lımlan

\begin{tabular}{lll}
\hline Konu alanı & $\mathbf{f}$ & $\mathbf{\%}$ \\
\hline öğretme-öğrenme yaklaşımları & 48 & 23,88 \\
Öğretmen & 39 & 19,40 \\
program geliştirme & 23 & 11,44 \\
program değerlendirme & 22 & 10,95 \\
Öğrenci & 13 & 6,47 \\
Değer eğitimi & 10 & 4,98 \\
Ĕgitim ve bilgi teknolojileri & 10 & 4,98 \\
Eğitim programı & 8 & 3,98 \\
Çok kültürlü eğitim & 8 & 3,98 \\
Uluslararasılaşma & 5 & 2,49 \\
strateji öğretimi & 5 & 2,49 \\
Karşışaştırmalı eğitim & 4 & 1,99 \\
Diğer & 6 & 2,99 \\
Toplam & 201 & 100 \\
\hline
\end{tabular}

Öğretme-öğrenme yaklaşımları konu alanında yapılan tezler incelendiğinde $(n=48)$ en fazla ters yüz edilmişöğrenme $(n=5)$ ve otantik öğrenme $(n=5)$ alt temalarını çalışıldığı belirlenmiştir. Diğer alt temalar ise probleme dayalı öğrenme, farklılaştırılmış öğretim, argümantasyon, oyularla öğretim, öykü temelli öğretim, işbirlikli öğrenme, STEM, aktif öğrenmE, arttırılmış gerçeklik, yaratıc drama, basamaklı öğretim, bilişsel koçluk, 4MAT vb. gibi farklı strateji, model, yöntem ve tekniklerdir. Öğretmen teması altında yer alan tezler hizmet-içi öğretmenler $(n=14)$, aday öğretmenler $(n=13)$ ve öğretmen eğitimi ile ilgili olarak 3 alt temada yapılmışlardır. Hizmet-içi öğretmenler alt teması altında farklı konularda çalışmaların yer aldığı görülmüştür. En fazla ise meslekte ilk yıl deneyimleri, güçlükleri $(n=3)$, mesleğe yönelik tutum, de- 
ğer ( $n=2)$, özyeterlik ( $n=2)$, sürdürülebilir kalkınma algıları $(n=2)$ ile ilgili olarak yapıldığı görülmüştür. Aday öğretmenler alt teması altında ise en faza belli bir konuya ya da alana yönelik olarak özyeterlik $(n=4)$, problem çözme $(n=3)$, üst bilişsel farkındalık $(n=2)$ çalışılmıştır. Yanısıra tutum, eleştirel düşünme, öğrenme stratejileri, çalılma becerileri sürdürülebilir kalkınma, güdü teknopedogojik alan bilgisi vb. gibi konularda da çalışmalar yapılmıştır. Öğretmen eğitimi alt teması altında yapılan tezlerin ise en fazla mesleki gelişim $(n=2)$, öğretmen nitelikler $(n=2)$ konularındadır. Yanısıra etken öğretmenlik, mesleki kimlik, klinik uygulamalar, genel alan yeterliliği gibi konularında da çalışmalar yapılmıştır.

Program geliştirme alt teması altında farklı düzeylerde ve konularda program geliştirme çalışmaları yer almaktadır. En fazla ise eleştirel düşünme becerisi $(n=4)$, ögretim ilke ve yöntemleri dersi $(n=3)$, mesleki gelişimi destekleme $(n=2)$ ile ilgili program geliştirme çalışmaları yapılmıştır. Yanısıra genel konfeksiyon teknoloji dersi, fen öğretimi dersi, matematik, araştırma üretkenliğini destekleme, düşünme becerileri, eğitici program, kadına yönelik şiddet vb. gibi farklı konularda da çalışmalar mevcuttur. Program değerlendirme teması altında yer alan alt temalar incelendiğinde en fazla İngilizce $(n=7)$ öğretim programlarının değerlendirildiği bunu matematik $(n=2)$, Fen Bilimleri $(\mathrm{n}=2)$, öğretmen yetiştirme programlarının $(\mathrm{n}=2)$ değerlendirildiği çalışmaların olduğu belirlenmiştir. Ayrıca Beden eğitimi, polis etiği dersi, düşünme eğitimi dersi, teknoloji dersi, öğretim ilke yöntemleri dersi, EPÖ doktora programları, Lisans çekirdek programları vb. gibi konularda da program değerlendirme çalışmaları yapılmıştır.

Öğrenci teması altında ise farklı dersler ve konularla ilgili başarı, algı, kayg, tutum, zihin özellikleri, kopya çekme, güdü, strateji vb. gibi çalışmalar yer almaktadır. Değer eğitimi alt temasında ise mesleki değerler, ders kitaplarında yer alan değerler, değer eğitim programları, kültürel değerlere duyarlık vb. gibi farklı konularda çalışmalar yer almaktadır. Eğitim ve bilgi teknolojileri temasında sosyal paylaşım siteleri, çevrim içi öğrenme, etkileşimli tahta, uzaktan eğitim uygulamaları, e değerlendirme, bilgisayar destekili eğitim yazılımları vb. gibi farlı konularda çalışmalar yer almaktadır. Eğitim programı alt temasında ise en fazla örtük program $(n=5)$ yapılmıştır. Ayrıca ihmal edilen program, eğitim durumları standartları, cumhuriyet dönemi eğitim programları ile ilgili tezlerde mevcuttur. Çok kültürlü eğitim teması 
altında öğretmen alg1 ve yeterlilikleri ile ilgili $(n=4)$, Çok kültürlü eğitim uygulamaları $(n=3)$, çok kültürlü eğitim le ilgili değişkenler $(n=1)$ alt temaları ile ilgili çalışmalar yapılmıştır. Uluslararasılaşma alt temasında uluslararası bakalorya programı, uluslarası eğitim programı, Türk üniversitelerinde uluslarasılaşma vb. konularında çalışmalar yapılmıştır. Karşılaştırmalı eğitim teması altında Türkiye -ABD, Almanya-Türkiye, Türkiye-Kazakistan ve Türkiye-diğer ülkeler eğitimin farklı konu başlıklarında karşılaştırmaların yapıldığı 4 tez olduğu belirlenmiştir.

\section{Tartışma ve Sonuç}

Araştırma sonucunda 2015-2019 yılları arasında EPÖ alanında en fazla tezin 2018 yılında tamamlandığı belirlenmiştir. Araştırmaya katılan üniversiteler içinde sırasıyla en fazla tezin Osmangazi Üniversitesinde yapıldığı bunu sırasıyla Abant İzzet Baysal, Çukurova, Hacettepe, Gaziosmanpaşa ve Gaziantep Üniversite'lerinin takip ettiği, en az tezin ise Afyon ve Ege Üniversite'sinde tamamlandığı belirlenmiştir. Bıkmaz ve diğerleri (2013) 1974-2009 yılları arasında EPÖ alanında en çok doktora tezinin OTTÜ, Hacettepe ve Ankara Üniversitesinde tamamlandığını belirlemişlerdir. Kozikoğlu ve Senemoğlu (2015) ise 2009-2014 yılları arasında EPÖ alanında yapılan doktora tezleri inceledikleri çalışmalarında en fazla tezin Fırat ve Abant İzzet Baysal Üniversitesi'nde tamamladığını belirlemişlerdir. Bu araştırma da ulaşılan sonuçlar açısından Abant İzzet Baysal Üniversitesi'nin Kozikoğlu ve Senemoğlu'nun (2015) çalışmasında belirlenmiş olan en fazla tez tamamlanan üniversitelerden biri olarak devam ettiğini göstermektedir. Hacettepe üniversitesi de B1kmaz ve diğerlerinin (2013) belirlediği bulgulara paralel olarak en fazla tez yapılan üniversitelerden biridir. Kozikoğlu ve Senemoğlu (2015) nun çalışmalarında belirtildiği gibi bu çalışmada da OTTÜ, Ankara gibi üniversitelerde tamamlanan tez sayılarındaki azalma görülmüştür. Tamamlanan tez sayılarının 2016 ve 2019 yılı dışında genel olarak artış gösterdiği belirlenmiştir. Tavşancil vd (2010), Bıkmaz vd. (2013) ve Kozikoğlu ve Senemoğlu'nun (2015) çalışmalarında da son yıllarda tez sayılarının giderek arttı̆ı belirlenmiştir. Bu çalışmada 2019 yılı tezlerinin önemli bir bölümünün erişime kapalı olması 2019'daki sayının azlığını açıklamaktadır. Ancak 2016 yılında tez sayılarındaki azalmanın 15 Temmuz nedeni ile ilgili olarak üniversitelerde yaşanan olumsuzlukların etkisi gösterilebilir. 
EPÖ doktora tezlerini yapan araştırmacıların sayıları kadın araştırmacılar lehine çok az farklı olsada yaklaşık olarak eşit olduğu söylenebilir. Sonuç Bıkmaz vd (2013) çalışma sonuçları ile paralellik göstermektedir. EPÖ doktora tezlerini yöneten erkek öğretim üyelerinin sayısı kadın öğretim üyelerine göre daha fazladır. Bu durum alanda çalışan kadın erkek öğretim üyeleri sayıları arasındaki dengeden kaynaklanabilir. Araştırmada yer alan doktora tezleri daha çok Profesör öğretim üyelerince yönetilmiştir. En az ise; Doktor Öğretim üyeleri tarafından tezler yönetilmiştir. Bu durumdan öğrencilerin danışman seçiminde akademik unvanı dikkate aldıkları sonucu çıkarılabilir. Yanı sıra EPÖ doktora programlarında akademik unvana göre danışman atamalarının yapıldığı sonucu da çkarılabilir.

Araştırma da yer alan doktora tezlerinin 84'ü karma (\%41,79), 64'ü nicel $(\% 31,84)$ ve 51'i $(\% 25,37)$ nitel yöntemle yapılmıştır. Bu sonuçlara göre incelenen doktora tezlerinde en fazla nicel ve nitel yöntemlerin birlikte kullanıldığı karma yöntemle çalışmaların yapıldığı söylenebilir. Kozikoğlu ve Senemoğlu'da (2015) tezlerde benzer bir biçimde sırasıyla en çok karma yöntemlerin $(\% 51,2)$, nicel yöntemlerin $(\% 34,7)$ ve nitel yöntemlerin $(\% 14,0)$ kullanildığı belirlemişlerdir. Schreglmann (2016) EPÖ lisansüstü tezlerini inceledikleri çalışmalarında da karma yöntemin daha çok tercih edildiğini belirlemişlerdir. Ancak Bıkmaz vd (2013) 1974-2009 yılları arasında EPÖ doktora tezlerinin inceledikleri çalışmalarında tezlerin \%55,9'unda nicel, \% 36'sının karma ve \%8,1'inde nitel yöntemlerin kullanıldığını belirlemişlerdir. Bıkmaz vd.'nin (2013) çalışmalarına benzer bir biçimde alanyazında EPÖ alanında yapılan lisansüstü tezlerde nitel yöntemlerin daha az kullanıldığını gösteren çalışmalar yer almaktadır. (Altın, 2004; Saracaloğlu ve Dursun, 2010). Eğitim bilimleri alanında da makale ve lisansüstü tezlerde nitel yöntemlere göre daha çok nicel yöntemlerin tercih edildiğini gösteren araştırma bulguları (Tavşancıl vd, 2010; Saban vd, 2010) alanyazında yer almaktadır. Ozan ve Köse'de (2014) EPÖ alanında yapılmış olan makaleleri incelediği çalışmalarında en fazla nicel yöntemlerin kullanıldığını belirlemişlerdir. Uyar (2016) ise EPÖ alanında yabancı bir dergideki 2002-2015 yılları arasında ki yayımlanan makaleleri incelediği çalışmasında, makalelerin araştırma yöntemlerinin daha çok nitel ve kuramsal türde olduğunu, karma yöntemlerin daha az kullanıldığını belirlemiştir. 
Araştırma da nicel yöntemlerle gerçekleştirilen çalışmalar içinde betimsel desenin deneysel desene göre daha fazla kullanıldığı belirlenmiştir. Kozikoğlu ve Senemoğlu'da (2015) araştırma deseni olarak sırasıyla en çok tarama/betimsel desenlerin $(\% 56,2)$, nicel deneysel desenlerin $(\% 30,6)$ ve nitel desenlerin $(\% 13,2)$ izlediğini belirtmektedirler. Ozan ve Köse $(2014)$ ve Schreglmann'da (2016) çalışmalarında nicel yöntemlerin daha çok betimsel ya da ilişkisel tarama türünde olduğunu belirlemişlerdir. Bıkmaz vd (2013) ise nicel desenler içinde ise yarısının nicel betimsel $(\% 50,0)$, yarıya yakınında da nicel deneysel $(\% 43,6)$ desende olduğu sonucuna ulaşmışlardır. Kozikoğlu ve Senemoğlu'da (2015)'de saptadığı gibi tarihsel olarak bakıldığında nicel yöntemler içinde deneysel desenin kullanımının azaldığı görülmektedir. Bıkmaz vd. (2013) 1974-2009 yılları arasında EPÖ doktora tezlerini inceledikleri çalışmalarında; başlangıçta tezlerde daha çok kullanılan nicel betimsel desenlerin yanında karma ve nitel desenlerin kullanımında artış yaşandığını ortaya koymuşlardır. 1999-2009 yılları arasında Hacettepe, Çukurova, Selçuk, Fırat, Abant İzzet Baysal ve Dokuz Eylül Üniversitelerinde daha çok deneysel desenin Ottü, Ankara, Atatürk, Anadolu ve İnönü Üniversitelerinde ise betimsel desenin daha fazla tercih edildiğini belirlemişlerdir. Aynı yıllar aralığın da 234 doktora tezinin 104'ünde karma ve 20'sinde nitel desenlerin kullanıld1ğını da saptamışlardır. Nitel desenleri ise OTTÜ ve Hacettepe üniversitelerinin kullandığını belirlemişlerdir.

Bu araştırma da ulaşılan sonuçlar; 1999 ve sonrasında karma desende yapılan çalışmaların artışının devam ettiğini göstermiştir. Bu durumda 20142019 yılları arasında EPÖ alanındaki yapılan doktora tezlerinde nicel ve nitel yöntemleri birarada kullanarak her iki yöntemin avantajlarından yararlanılmaya çalışıldığını göstermektedir. Ayrıca önceki yıllarda yapılan çalışmalara göre derinlemesine incelemenin yapılmasına olanak sunan nitel çalışmalarında arttığ1 da belirlenmiştir. Bu durum hem genel de lisansüstü hem de özelde EPÖ alanında lisansüstü eğitimlerde nitel araştırma derslerinin verilmesi, alanda nitel araştırma konusunda kaynak teşkil edebilecek yayınların artmasından kaynaklanmış olabilir.

Araştırma kapsaminda incelenen tezlerin örneklemin de en fazla öğretmenlerin ve öğretmen adaylarının olduğu belirlenmiştir. Bu sonuç EPÖ alanında tez ve makaleleri inceleyen çalışmalarla paralellik göstermektedir (Bıkmaz vd, 2013; Kozikoğlu ve Senemoğlu, 2015, Ozan ve Köse, 2014). Araştırma kapsamında incelenen tezlerde öğretmenleri ve öğretmen adaylarını sırasıyla 
ortaokul öğrencileri, öğretim elemanları ve öğretmen adayları dışında kalan lisans öğrencileri, ilkokul ve lise öğrencileri izlemektedir. Bıkmaz vd.'nin (2013) çalışmalarında ise öğretmen adaylarından sonra ilkokul öğrencileri yer almaktadır. Kozikoğlu ve Senemoğlu ise (2015) lisans, ortaokul öğrencilerinin ve öğretim elemanlarının daha fazla çalışmalarda yer aldıklarını belirlemişlerdir. Alanyazın da EPÖ ve eğitim bilimleri alanında yapılmış tez ve makaleler de örneklem olarak lisans öğrencilerinin de çok tercih edildiği görülmektedir (Arık ve Türkmen, 2009; Bıkmaz vd, 2009; Fazlıŏulları ve Kurul, 2012; Kozikoğlu ve Senemoğlu, 2015).

$\mathrm{Bu}$ araştırma da incelenen tezlerin örneklem grupları içerisinde okulöncesi ve lisansüstü öğrenciler ise öğrenci grupları içinde en düşük düzeydedir. Ayrıca mezunlar, vatandaş, fiziksel mekanlar ve işverenlerinde az sayıda örneklemlerde yer aldığı belirlenmiştir. Bıkmaz vd. (2013) çalışmalarında da benzer biçimde okul öncesi ve lisansüstü öğrencilerinin, mezunların ve müfettişlerin çok az sayıda tezlerin örnekleminde yer aldıklarını belirlemişlerdir. Kozikoğlu ve Senemoğlu ise (2015) tezlerde lise ve lisansüstü öğrencilerinin örneklem olarak sayısının çok az olduğunu belirtmektedir. Ozan ve Köse'de (2014) okulöncesi ve lisansüstü öğrencilerinin örneklem olarak araştırmalarda çok az sayıda yer aldıklarını belirlemişlerdir. Buna göre 2009 ve sonrasında yapılan çalışmalarda öğrenciler açısından ilkokul öğrencilerinin yerine ortaokul ve lisans öğrencilerinin yer aldığı sonucu çıkarılabilir. Bu durum lisans öğrencilerinden daha kolay veri toplama nedeninden kaynaklanabilir. Ortaokul öğrencileri ise okulöncesi ve lisansüstü eğitime göre daha kolay uygulamaya firsat sunduğu için daha fazla tercih edilmiş olabilir.

Araştırma da tezler örneklem büyüklükleri açısından incelendiğinde tezlerin en fazla 1-50 arasında olduğu belirlenmiştir. Ozan ve Köse (2014) yaptıkları çalışmalarında örneklem büyüklüklerinin en çok 301-1000 arası olduğunu belirlemişlerdir. Ozan ve Köse (2014) örneklemin büyüklüklerinin fazla olmasını araştırmalarında yer alan makalelerin daha çok betimsel tarama deseninde yapılmış olması ile açıklamışlardır. Kozikoğlu ve Senemoğlu ise (2015) örneklem büyüklüğü bakımından, tarama/betimsel çalışmalarda örneklemin 1000 ve üzerinde, deneysel çalışmalarda 31-100 arasında ve nitel çalışmalarda 100 ve altında olduğunu belirlemişlerdir. Bıkmaz vd. (2009) ise çalışmalarında betimsel desenli tezlerde örneklem büyüklüğünün 9 ile 3484, deneysel çalışmalarda ise 3 ila 220 arasında olduğunu belirlemişlerdir. Bu çalışmada nitel, karma ve nicel deneysel yöntemin kullanıldığı araştırmaların 
toplam sayısı daha geniş örneklemlerde yapılan nicel betimsel tarama çalışmalarına göre oldukça fazladır. Ayrıca karma desenli çalışmaların diğer desenlerden daha çok yapılmış olması ve karma desenli çalışmaların daha çok deneysel desenle birlikte nitel veri toplama araçlarının kullanılması ile dizayn dilmiş olması örneklem büyüklüklerinin daha çok 1-50 arasında olmasını açıklayabilir.

Araştırmada tezler veri çözümleme teknikleri açısından incelendiğinde en fazla içerik çözümlemesinin kullanıldığı belirlenmiştir. Bunu sırasıyla t- Testi, betimsel çözümleme, frekans ve yüzde, Anova, Non parametrik testlerin kullanımı izlemiştir. İncelenen tezlerde en az Kanonik korelasyon çözümlemesi ve Aşamalı doğrusal modelleme kullanılmıştır. Araştırma da karma desenlerin kullanılması nedeniyle hem nicel hem de nitel çözümlemeler kullanımı fazladır. Kozikoğlu ve Senemoğlu (2015) çalışmalarında sırasıyla en fazla frekans, yüzde, ortalama, standart sapma (tek değişkenli analizler), korelasyon, ki-kare, t-testi, Anova, Manova, Kruskas Wallis analizleri (korelasyonel analizler) ve nitel analizlerin (betimsel ve içerik analizi) kullanıldığını belirlemişlerdir. En az ise regresyon, yol analizi, yapısal eşitlik (yordamsal analizler) analizlerinin kullanıldığını saptamışlardır. Bu çalışmada en fazla içerik analizinin kullanılmış olması nitel, karma yöntemlerin daha fazla sayıda gerçekleştirilmiş olması ile açıklanabilir.

Araştırmada veri toplama araçları açısından incelendiğinde tezlerde sırasıyla en fazla likert ölçek, yarı yapılandırılmış görüşme, katılımcı olmayan gözlem, çoktan seçmeli başarı testi, dökümanlar ve günlüklerin kullanıldığı görülmektedir. Araştırma da en az açık uçlu başarı testi, fotoğraflar, video kayıtları ve öğrenci ürünleri kullanılmıştır. Bıkmaz vd. (2009) daha çok başarı testlerinin, Schreglmann (2016) ölçeklerin ve görüşme formunun, Ozan ve Köse (2014) ve Kozikoğlu ve Senemoğlu ise (2015) en çok sırasıyla ölçek/envanter, görüşme formu, anket, başarı testi ve gözlem formu kullanıldığnı belirlemişlerdir. Özan ve Köse (2014) bu çalışmada da ortaya koyulduğu biçimde görüşmelerin yarı yapılandırılmış, gözlemlerin katılımcı olmayan gözlem ve testlerin çoktan seçmeli testler olduğunu belirlemişlerdir. Bıkmaz vd (2009) en az kullanılan veri toplama aracının günlük - yansitma defteri ile proje ve senaryolar olduğunu, Kozikoğlu ve Senemoğlu (2015) ise günlük, video-ses kayıtları, senaryolar olduğunu belirlemişlerdir. Ozan ve Köse (2014) çalışmalarında da incelenen EPÖ makalelerinde günlük, senaryo, vi- 
deo kayıtları vb. gibi nitel veri toplama araçlarının kullanımına ait veri yoktur. Bu çalışma 2015-2019 EPÖ doktora tezlerinde günlüklerin sıkça kullanıldığı göstermektedir. Video kayıtları ve senaryolarında az sayıda da olsa kullanıldığı belirlenmiştir. 2015-2019 yılları arasında EPÖ doktora tezlerinde likert ölçeklerin en fazla kullanılmasının nedeni hem nicel, hem de karma yöntem araştırmalarında kullanılmalarından kaynaklanmaktadır. Likert tipi ölçekleri yarı yapılandırılmış görüşmelerin izlemesi ise araştırmada karma ve nitel çalışmaların nicel yöntemlerden fazla kullanılması ile açıklanabilir.

2015-2019 EPÖ doktora tezlerinde en fazla araştırılan konu alanlarının öğretme-öğrenme yaklaşımları, öğretmenler (öğretmen adayları, öğretmen eğitimi ve hizmet-içinde yer alan öğretmenler), farklı konu alanları ve düzeylerde yapılan program geliştirme ve program değerlendirme çalışmaları, öğrenci özellikleri, değer eğitimi ve eğitim ve bilgi teknolojileri ile ilgili yapıldığı belirlenmiştir. Bu sonuçlar özellikle ilk sırada öğretme yaklaşım ve tekniklerinin olması ile alanyazında EPÖ alanında araştırma eğilimlerinin incelendiği çalışmalarla benzerlik göstermektedir (Bıkmaz vd, 2013; Kozikoğlı ve Senemoğlu, 2015; Ozan ve Köse, 2014; Saracaloğlu ve Dursun, 2010). Bıkmaz vd. (2013) çalışmalarında program değerlendirmenin en az çalışılan konular arasında yer aldığı belirlemişlerdir. Kozikoğlu ve Senemoğlu, (2015) özellikle 2005-2006 yılında MEB'in programlarda yaptığı değişikler nedeniyle program değerlendirme çalışmalarının 2009-2014 yıllarında en çok çalışılan ikinci konu olduğunu belirlemişlerdir. Yetkiner, Acar, Erdol ve Ünlü (2019) 19962017 yılları arasında EPÖ alanında program değerlendirme ile ilgili yapılan doktora tezlerinde tezlerin daha çok örgün eğitim programlarının ele alındığını belirlemişlerdir. 2015-2019 yıllarının incelendiği bu çalışmada da MEB programlarının değerlendirildiği, yanısıra lisans programları, değişim programları vb. gibi farklı konularda da çalışmaların yapıldı ̆̆ı görülmektedr. Kozikoğlu ve Senemoğlu, (2015) ve Bıkmaz vd. (2013) program geliştirme çalışmalarının da az çalışılan konular arasında yer aldığını belirlemişlerdir. Yapılan bu çalışma 2015-2019 EPÖ doktora tezlerinde birçok konu alanı ve düzeyinde program geliştirme çalışmalarında önceki yılara göre bir artışı olduğunu göstermektedir. Yapılan bu çalışma da en az çalışılan konular ise; eğitim programı ögeleri, çok kültürlü eğitim, uluslararasılaşma, strateji öğretimi ve karşılaştırmalı eğitimdir. Bıkmaz vd. (2013) içerik seçimi ve düzenlenmesi, ölçme ve değerlendirme, program model önerileri, değer öğretimi ve örtük 
program gibi konuların doktora çalışmalarında yer almadığını belirlemişlerdir. 2015-2019 EPÖ doktora tezlerinde da az sayıda da olsa değer eğitimi ve örtük program konularının çalışıldığı belirlenmiştir. Kozikoğlu ve Senemoğlu, (2015) ise çalışmalarında en az yaygın eğitim programlarının değerlendirilmesi, öğretme-öğrenme ortamı, özel eğitim ve çevre eğitimi konularına yer verildiğini belirlemişlerdir. 2015-2019 EPÖ doktora tezlerinde de benzer biçimde bu konularda çalışmalar çok az ya da yoktur.

Araştırmadan elde edilen sonuçlara göre EPÖ doktora tezlerinde okulöncesi ve lisansüstü öğrenciler ile mezunlar, vatandaş, fiziksel mekanların örneklem olarak daha az seçildiği belirlenmiştir. Araştırmacılara çalışmalarında bu örneklem gruplarına yer vermeleri önerilebilir. Çalışmada konu alanı olarak az çalışma yapıldığı ya da hiç çalışma yapılmamış olan eğitim programlarının kuramsal temelleri, eğitim programı ögeleri, çok külttürlü eğitim, uluslararasılaşma, strateji öğretimi, karşılaştırmalı eğitim, yaygın eğitim programlarının değerlendirilmesi, öğretme-öğrenme ortamı, özel eğitim ve çevre eğitimi konularında çalışmalar yapmaları önerilebilir. Bu araştırma da veri toplama araçları olarak nitel ve karma çalışmalarda az sayıda kullanılan video, fotoğraflar, senaryoların kullanımına da yer verilebilir. EPÖ alanındaki eksiklerin ve araştırma eğilimlerinin belirlenmesi için EPÖ lisansüstü çalışmalarının belirli aralıklarla periyodik olarak incelenmesi araştırmacılara önerilebilir. 


\title{
EXTENDED ABSTRACT
}

\section{Investigating the Doctoral Theses in The Field of Curriculum and Instruction:2015-2019}

\author{
* \\ Neşe Özkal \\ Alanya Alaaddin Keykubat University
}

The undergraduate department in the Curriculum and Instruction (C\&I) program founded in 1971 in Turkey to provide education at undergraduate level was closed down in 1997. Since 1997, the C\&I program accepts graduate students and contributes to the field with master's and doctoral theses (Kozikoğlu and Senemoğlu, 2014). Regarding the systematic review of C\&I doctoral theses, the most comprehensive studies providing the content analysis for C\&I doctoral theses were conducted by Bikmaz et. al. (2009) for the period between 1974-2009 and by Kozikoğlu and Senemoğlu (2014) for the period between 2009-2014 as the continuation of the study conducted by B1kmaz et. al. (2009). It is recommended that studies with such qualifications be conducted regularly in five-year periods in order to determine research trends (Karadağ, 2010). Therefore, this study aimed to determine the current research trends in doctoral theses in the field of C\&I for the period between 2015-2019 as a continuation and complementary of these two studies identified before. It is believed that the current study will guide the researchers working in the field of C\&I in organizing their research by contributing to identification of research trends and the gaps and thus will contribute to the field.

Qualitative research method and document analysis technique were used in the study. The documents used in this study were the doctoral theses taken as samples. The sample of the study consisted of 201 doctoral dissertations presented in the field of C\&I for the period between 2015-2019, with open access from the Council of Higher Education thesis database. The analysis of the research data was carried out by analyzing the descritive and content analysis of 201 doctoral dissertations in the sample. Theses in this study were examined with the thesis review form which was developed by the researcher. In addition, the coding used in the study for the themes related to the research subject was examined by content analysis. 
Based on the study results, it was determined that the highest number of dissertations for the period of 2015-2019 was completed in 2018. Among the universities that participated in the study, Osmangazi University had the highest number of dissertations while Afyon and Ege Universities had the least number. The number of researchers doing C\&I doctoral theses was approximately equal. The number of male faculty members overseeing the C\&I doctoral theses was found to be higher than those of female faculty members. The doctoral theses in the research were directed by professors the most and by doctoral lecturers the least. In doctoral theses, the methods most commonly used were mixed, quantitative and qualitative methods respectively. It was identified that teachers and prospective teachers were selected as the sample of theses the most. Compared to the other students, preschool students and graduate students were the groups less preferred as sample groups in C\&I theses. When the theses were examined in terms of sample size, it was determined that sample sizes were between 1-50 and the content analysis techniques were used the most as data analysis technique. In the theses examined in the framework of this study, canonical correlation analysis and graded linear modeling were found to be used the least. The fact that sample size was 150 the most and that content analysis was used in general can be explained by the preference towards using qualitative and mixed methods in these theses. The data were mostly collected with Likert scale, semi-structured interview, non-participant observation, multiple choice achievement test, documents and diaries. Open-ended achievement test, photographs, video recordings and student products were used the least. This study shows that diaries were frequently used in the C\&I doctoral theses submitted in the period of 2015-2019 and that video recordings and scenarios were also utilized, albeit in a small number. The fact that Likert scales and semi-structured interviews were mostly used in C\&I doctoral theses in the period of 2015-2019 may be explained with use of mixed and qualitative studies more than the quantitative methods. The most common research fields in 2015-2019 C\&I doctorate theses were found to be teaching and learning approaches, teachers (teacher candidates, teachers in teacher training and in-service training), program development and program evaluation studies in different subject areas and levels, student characteristics, value education and education and information technologies. This study, which examined the period of 2015-2019, found that MoNE programs were evaluated, as well as other subjects of interest such as 
undergraduate programs, exchange programs and so on. This study shows an increase in program development studies in many subject areas and levels in C\&I doctoral theses in the period of 2015-2019 compared to previous. The least studied subjects were identified as elements of training programs, multicultural education, internationalization, strategy teaching and comparative education. It was identified that value education and implicit program were studied, albeit in a small number in 2015-2019 C\&I doctorate theses. According to the results obtained from the research, it may be suggested to carry out studies in C\&I doctoral theses with research areas, sample groups, and education levels that are less studied or not previously studied. Periodic review the C\&I graduate studies is recommending in order to identify these shortcomings.

\section{Kaynakça / References}

Altın, N. (2004). Eğitim programları ve öğretim alanında yapılan yüksek lisans tezlerinin analizi:Ankara, Gazi ve Hacettepe Üniversitesi. Yayımlanmamış yüksek lisans tezi, Ankara Üniversitesi, Ankara.

Arık, R. S. ve Türkmen, M. (2009). Eğitim bilimleri alanında yayımlanan bilimsel dergilerde yer alan makalelerin incelenmesi. 10.09.2019 tarihinde http://www.eab.org.tr/eab/2009/pdf/488.pdf adresinden erişildi.

Bıkmaz, F. H., Aksoy, E., Tatar, Ö. ve Altınyüzük, C. A. (2013). Eğitim programları ve öğretim alanında yapılan doktora tezlerine ait içerik çözümlemesi (1974-2009). Eğitim ve Bilim Dergisi, 38 (168), 288-303.

Boyacı, S. ve Demirkol, S. (2018). Türkçe eğitimi alanında yapılan doktora tezlerinin incelenmesi. Ana Dili Eğitimi Dergisi, 6(2), 512-531.

Creswell, J. W. (2014). Nitel araştırma yöntemleri beş yaklaşıma göre nitel araştırma ve araştırma deseni. (M. Bütün ve S. Beşir Demir, Çev.), Ankara: Siyasal Kitabevi (2013).

Demirel, Ö., Ayvaz, Z. ve Köksal, N. (2008). Eğitim programları ve öğretim alanında yapılan tezlerin konularının ve yöntemlerinin incelenmesi. II. Lisansüstü eğitim sempozyumu (26-28 Eylül 2008) bildiri kitabı, 64-69.

Demirhan İşcan, C. ve Hazır Bıkmaz, F. (2012). Eğitim programları ve öğretim alanında lisansüstü eğitim programlarının analizi ve öneriler. Eğitim Bilimleri Fakültesi Dergisi, 45(1), 107-138.

Erişti, B. (2013) Türk üniversitelerinde eğitim programları ve öğretim anabilim dalında görev yapan öğretim elemanlarının profilleri. Eğitim ve Bilim, 38(167), 312-326. 
Fazlıoğulları, O. ve Kurul, N. (2012). Türkiyedeki eğitim bilimleri doktora tezlerinin özellikleri. Mehmet Akif Ersoy Üniversitesi Ĕ̆itim Fakültesi Dergisi, 12(24), 43-75.

Gömleksiz, M. N. ve Bozpolat, E. (2013). Eğitim programları ve öğretim alanındaki lisansüstü tezlerin değerlendirilmesi. The Journal of Academic Social Science Studies, 6(7), 457-472. Doi: 10.9761/JASSS1769

Karadağ, E. (2009). Türkiye'de eğitim bilimleri alanında yapılmış doktora tezlerinin tematik ve metodolojik açıdan incelenmesi: Bir durum çalışması. Yayımlanmamış doktora tezi, Marmara Üniversitesi, İstanbul.

Karadağ, E. (2010). Eğitim bilimleri doktora tezlerinde kullanılan ölçme araçları: Nitelik düzeyleri ve analitik hata tipleri. Kuram ve Uygulamada Eğitim Bilimleri, 11(1), 311-334.

Kozikoğlu, İ. ve Senemoğlu N. (2015). Eğitim programları ve öğretim alanında yapılan doktora tezlerinin içerik analizi (2009-2014). Eğitim ve Bilim, 40(182), 29-41.

Miles, M. B. ve Huberman, A. M. (1994). Qualitative data analysis. Thousand Oaks, CA: Sage.

Ozan, C. ve Köse, E. (2014). Eğitim programları ve öğretim alanındaki araştırma eğilimleri. Sakarya Üniversitesi Journal of Education, 4(1), 116-136.

Özdemir, M. Ç., ve Arı, A. (2008). Eğitim programları ve öğretim bilim dalında yapılmış bazı doktora tezlerinin incelenmesi. H. Gümüş, O. Ramazan, ve E. Esmer (Ed.), II. Lisansüstü Ĕ̆itim Sempozyumu bildiriler kitabı, içinde (s.40-63).

Saban, A., Koçbeker-Eid, B. N., Saban, A., Alan, S., Doğru, S., Ege, İ, Arslantaş, S., Çınar, D. ve Tunç, P. (2010). Eğitimbilim alanında nitel araştırma metodolojisi ile gerçekleştirilen makalelerin analiz edilmesi. Selçuk Üniversitesi Ahmet Keleşoğlu Ĕ̆itim Fakültesi Dergisi, 30, 125-142.

Saracaloğlu, A. ve Dursun, F. (2010). Türkiye'de eğitim programları ve öğretim alanındaki lisansüstü tezlerin incelenmesi. 1. Ulusal Eğitim Programları ve Öğretim Kongresi, 15-17 kasım, Ankara.

Schreglmann, S. (2016). Türkiye'de program geliştirme konusu ile ilgili yapilan yüksek lisans ve doktora tezlerinin içerik analizi. Uluslararası Sosyal Araştırmalar Dergisi, 9(43), 1492-1500. Doi: $10.17719 / j i s r .20164317720$ 
Tavşancıl, E., Çokluk, Ö., Gözen-Çıtak, G., Kezer, F., Yıldırım, Y.Ö., Bilican, S., Büyükturan, E.B., Şekercioğlu, G., Yalçın, N., Erdem, D., Özmen, D.T. (2010). Eğitim bilimleri enstitülerinde tamamlanmış lisansüstü tezlerin incelenmesi (2000-2008). Ankara Üniversitesi Bilimsel Araştırma Projesi Kesin Raporu.

Uyar, M. Y. (2017). Eğitim programları ve öğretim alanına yönelik bir dergideki araştırmalara ilişkin içerik analizi: 2002-2015. Kastamonu Eğitim Fakültesi Dergisi, 25(3), 1008-1024.

Yetkiner, A., Acar, Erdol, T. ve Ünlü, Ş. (2019). Content analysis of phd dissertations on curriculum evaluation (1996-2017). Erzincan University Journal of Education Faculty, 21(1), 247-269. Doi: 10.17556/erziefd.443298

\section{Kaynakça Bilgisi / Citation Information}

Özkal, N. (2020). Eğitim Programları ve Öğretim Alanında Yapılan Doktora Tezlerinin İncelenmesi: 2015-2019. OPUS-Uluslararası Toplum Araştırmaları Dergisi, 15(25), 3415-3442. DOI: 10.26466/opus.647030 